\title{
Bio-physical linkages in coastal wetlands - implications for coastal protection
}

\author{
I. Möller \\ Cambridge Coastal Research Unit, Department of Geography, and Fitzwilliam College, University of Cambridge, CB2 3EN, \\ Cambridge, UK, iris.moeller@geog.cam.ac.uk
}

\begin{abstract}
Coastal wetlands have, for many decades, fascinated ecologists and geomorphologists alike. The existence of terrestrial vegetation communities in highly saline and hydraulically extremely dynamic environments has provided an ideal opportunity to study both ecological adaptation mechanisms to physical stressors as well as the importance of vegetation to landform evolution. In recent years, however, the importance of understanding the linkages between the biological and physical factors that control coastal wetland functioning and evolution has been brought into focus within the conservation, engineering, and policy sector. This is largely the result of a rising awareness of the value of coastal wetlands resulting from the services they provide to society. Those services include their role as natural sea defenses, a role that is becoming increasingly significant in the context of ever increasing coastal population densities alongside environmental pressures (e.g. sea level rise and increasing storm frequencies) arising from climate change. This paper reviews how, over the past quarter of a century, advances in field, laboratory, and numerical modeling approaches have made particular inroads into the quantification of the sea defense role of coastal wetlands. It is becoming increasingly clear that the sea defense function itself is complex and highly context dependent. Although there is now an urgent need for improved ecologicallyinformed engineering solutions, these are unlikely to be successful without future research finding appropriate ways of scaling up hydraulically important parameters to the landscape scale and defining the physical and biological process thresholds that control the continued provisioning of the sea defense function of coastal wetlands in the face of potential extreme events and sea level rise.
\end{abstract}

\section{INTRODUCTION}

Coastal wetlands exist on most of the world's coastlines and their value has been brought to the attention of national and international conservation bodies through the recognition of the ecosystem services they provide [MEA, 2005; UKNEA, 2011]. While coastal wetlands have long been the focus of academic study, this recognition of their societal values, the increasing human pressures faced by, and climate change impacts on, these environments have been the catalyst for a stronger focus of coastal research on the linkages between biological and physical processes within coastal wetlands in recent years [Allen, 2000; Gedan et al., 2010; Spencer and Möller, 2012].

Coastal mangrove and saltmarshes provide a range of ecosystem services, with the UKNEA [2011] identifying particularly their provisioning (e.g. agricultural), climate regulatory (e.g. carbon sequestration [Chmura et al., 2003]), and hazard regulatory (e.g. flood defense and wave dissipation [Gedan et al., 2011] functions. Underpinning these particular functions are a range of 'supporting services', such as primary production, soil formation, water quality regulation, etc. [Beaumont et al., 2008]. The assessment (and quantification) of all of these functions requires a detailed understanding of bio-physical linkages within the wetland systems, but particular linkages become important with respect to particular services. The potential for individual services to exist in 'trade-off' relationships with other services must thus be kept in mind when focusing on any individual service.

This paper focuses on the importance of recent research into the bio-physical linkages within coastal wetlands, both saltmarshes and mangroves, for the assessment of the particular service of flood and storm protection. In doing so, several important biophysical linkages that determine the continued existence of coastal wetlands in particular environmental contexts are only briefly highlighted, but the reader is referred to the wealth of existing literature that addresses these wider controls on saltmarsh/mangrove functioning [Allen, 2000; Allen and Pye, 1992; Woodroffe, 2002].

\section{THE NATURE OF BIO-PHYSICAL LINKAGES IN COASTAL WETLANDS}

Coastal wetlands exist in the upper intertidal zone, characterized by halophytic vegetation communities and regular tidal inundation. While saltmarshes and mangroves differ markedly in vegetation structure, landform development, and geographical distribution (mangroves being restricted to the tropics [Woodroffe, 2002]), both types of wetland typify what can be seen as the most fundamental bio-physical linkage: vegetation mediates the coastal morphodynamic principle linkage between hydrodynamics and sediment transport through its modification of water flow paths and currents and sediment provision, capture, and retention (Fig. 1). Within this general relationship, it is important to remember the fundamental difference in the time-scale over which biological controls operate (generally beyond the seasonal time-scale) compared to the time-scale of hydrodynamic processes (seconds (e.g. waves) to seasonal (spring-neap tidal cycles)). Thus, over short, instantaneous time-scales (waves and tidal current flows), the presence of biota plays a rather passive part (i.e. providing an obstruction to currents or waves), while over longer, lagged, geomorphological time-scales ( $>$ annual), it becomes an active component of the dynamic morphological evolution of the system 


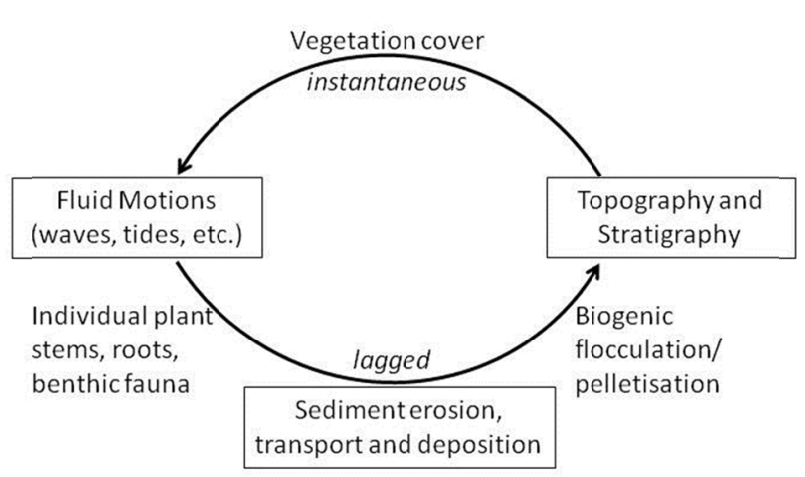

Figure 1. The influence of biota on the morphodynamic linkage between coastal morphology, fluid motions that interact with it, and sediment erosion, transport, and deposition [adapted from from Cowell and Thom, 1994].

as a whole (i.e. contributing to landform evolution directly and indirectly (Fig. 1)).

A large body of literature exists that addresses these general bio-physical feedbacks in more detail, with arguably the greatest volume of work addressing the feedbacks involved in controlling the wetland response to sea level rise. Here, the alteration of relative sea level through vertical growth of the marsh surface is facilitated by the dense vegetation cover decreasing flow velocities and turbulence upon inundation [see e.g. Christiansen et al., 2000; Leonard and Luther, 1995], as well as contributing organic material for marsh surface and sub-surface sedimentation [French, 2006] (Fig. 2).

Amongst other important insights, this body of work has highlighted that the multitude of bio-physical feedbacks that exist in wetland ecosystems operate on a vast range of time-scales and that time- and space- scales in wetland evolution are tightly linked as illustrated in Spencer and Möller's [2012] review of mangrove system functioning (Fig. 3). Furthermore, it has become increasingly obvious that the relationship between individual biological and physical parameters changes beyond certain, as yet largely undefined, process thresholds [Bouma et al., 2009; Koch et al., 2009; Morris et al., 2002].

\section{THE SEA-DEFENSE ROLE OF COASTAL WETLANDS}

The view that coastal wetlands act as important sea defenses has been voiced in the United States as early as the late $19^{\text {th }}$ Century [Gedan et al., 2011], but more formal scientific study into the sea defense role did not begin until the mid-1970s [Wayne, 1976], since when there have been numerous field, laboratory, and numerical modeling studies on the topic [Anderson et al., 2011; Gedan et al., 2011]. Before discussing these approaches in more detail, it is useful to highlight that, bound up in discussions on the sea defense role of coastal wetlands is the common failure to recognize that the 'sea defense' function itself is highly complex. There are two aspects to this complexity:

First, there are a series of hydrodynamic processes against which 'defense' may need to be provided. These include, for example, elevated water levels during meteorological surges or

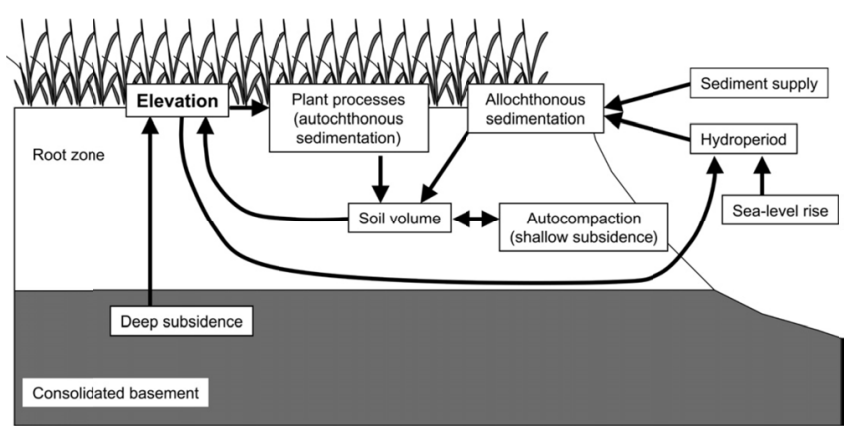

Figure 2. The range of biological and physical influences on the vertical adjustment of coastal marshes through surface sedimentation [French 2006 (adapteid from USGS 1994)].

river-flow induced estuarine floods: (such as in the Mississippi Delta [Wamsley et al., 2009]), storm generated waves, boat generated waves (a common cause of erosion in Venice lagoon [Dabala et al., 2005]), or tsunami waves (e.g. the Asian Tsunami of 2005 [Tanaka et al., 2007]). Although the first two of these hydrodynamic coastal threats, elevated water levels and wind generated waves, often coincide, each of these processes is rather different in nature and interacts with the wetland's vegetation and morphological features differently. It is thus unfortunate that many discussions of the 'sea defense' function of coastal wetlands do not recognize that protection against one threat does not necessarily afford the same protection against another and that different wetland properties potentially become significant in relation to different threats.

Secondly, the provision of efficient 'sea defense' requires either the dissipation of hydrodynamic energy incident upon the shore and/or an increased resistance of the shore to damage from hydrodynamic energy impacts. Investigations into the sea defense function of coastal wetlands must thus address both those factors that determine the resistance of the wetland to erosion and those factors that determine the degree to which the wetland affects the hydrodynamic process that poses the threat. Looking at the sea defense function of coastal wetlands from both these perspectives highlights the location-specific nature of this function: even in situations with identical hydrodynamic threats, the resistance of one wetland to erosion may be much lower than that of another, thus resulting in one wetland providling a 'better' (longer lasting) sea defense service.

The complexity of the sea defense function of coastal wetlands has only been openly addressed in recent reviews on the subject [Shepard et al., 2011; Gedan et all, 2011], but its recognition means that the translation of the results from scientific studies that focus on only one element of the process (e.g. the effect of the vegetation-induced surface roughness on waves) cannot easily be translated into engineering guidelines that must consider the full sea defense functionality of a wetland.

In recognition of some of the points raised above, Shepard et al. [2011] divide the sea defense function of coastal wetlands into wave attenuation, shoreline stabilization, and floodwater attenuation. For the purposes of this review, the resistance of wetlands to incident hydrodynamic energy (shoreline stabilization) will not be discussed in detail, but the reader is referred to Shepard et al. [2011] and to the reviews on the geomorphology of coastal 


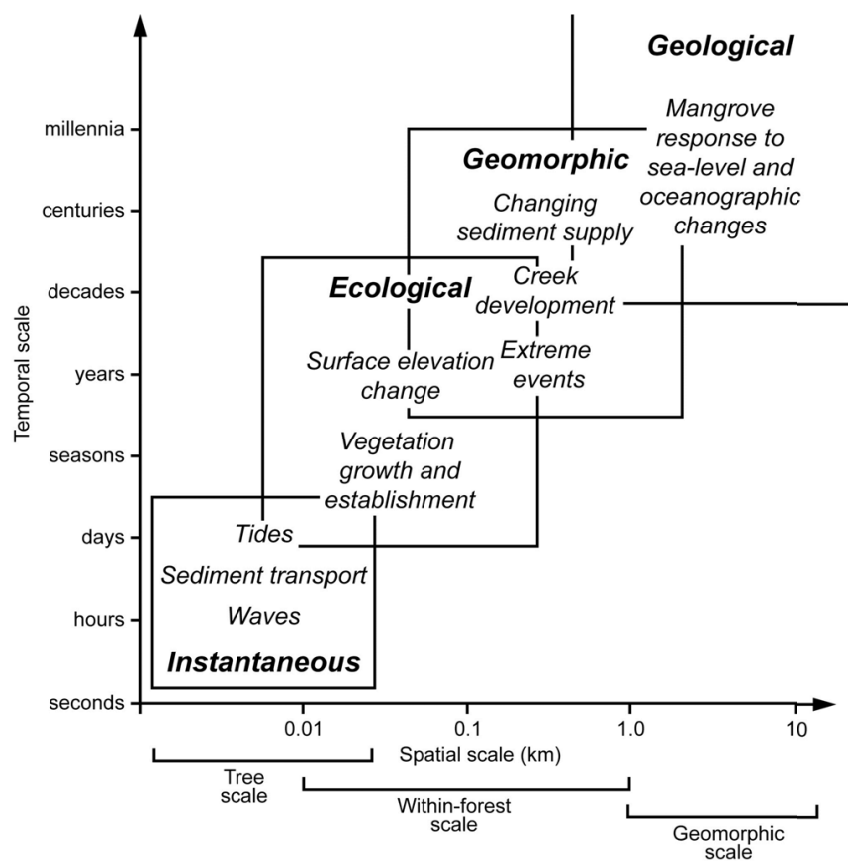

Figure 3. Time-space relationships of biological and physical processes within mangrove forest systems. Bio-physical linkages and feedbacks can be identified at a range of scales [from Spencer and Möller, 2012].

wetlands provided by Allen [2000], Woodroffe [2002], and Spencer and Möller [2012] and on the impact of extreme events on wetlands [Cahoon et al., 2006; Tanaka et al., 2007; Vermaat and Thampanya, 2006]. In view of the very different nature of tsunami waves compared to wind-generated waves, the seadefense role of wetlands as discussed here is thus most sensibly split into: (i) flood control (water level regulation), (ii) wind wave dissipation, and (iii) mitigation of tsunami damage. The linkages between biological and physical factors vary widely with respect to each one of these three functions, necessitating their separate discussion.

\section{Flood control}

The flood control function of coastal wetlands concerns the impact that the existence and location of a coastal wetland can have on regional or local water levels during flood events. This function could also be described as 'water flow regulation' and its specific operation depends on the cause of the flood event.

Flow retardation over vegetated intertidal surfaces at the small, vegetation canopy scale, is well documented through field and laboratory studies. Leonard and Luther [1995], for example, showed that turbulent kinetic energy in Juncus roemerianus wetlands in Florida and Spartina alterniflora marshes in Louisiana was reduced by up to $65 \%$ of the original energy after a distance of only $3 \mathrm{~m}$. While water depths in those micro-tidal field sites were low (under 45 and $20 \mathrm{~cm}$ in the Florida and Louisiana sites, respectively), such evidence suggests that significant flow retardation occurs over vegetated intertidal surfaces, thus slowing/delaying the progression of tidal flows / meteorological surges.

Numerical modeling studies (see below) have largely confirmed such flow reduction effects over wetland surfaces, though they have also highlighted that this flow reduction effect can be complex, and may produce zones of higher flow within the canopy, as in Shi et al.'s [1996] study on flows within saltmarsh (Spartina) vegetation. Fonseca and Cahalan [1992] recorded significant flow reduction ( $40 \%$ over a $1 \mathrm{~m}$ long test section) in seagrass beds, but observed a rapid reduction in flow reduction when water depth exceeded plant size. Plant height and alignment played an important role in controlling shear stress and current reduction in these experiments, but all laboratory studies indicate a strong interaction of the plants with the flow through hydrodynamic drag and the generation of turbulent eddies around the obstructions. In addition to plant height and alignment, stem density has proved to be of importance in determining shear velocities within the vegetated zone [Fonseca et al., 1982].

Within mangroves, evidence for such flow retardation at the landscape scale has been observed by Krauss et al. [2009] where, during two hurricanes, water levels were reduced by as much as $9.4 \mathrm{~cm} / \mathrm{km}$ across a mangrove area in Florida. Evidence for high friction effects on water levels is also provided by Wolanski et al. [1992], who report water surface slopes of up to $1 \mathrm{~m}$ per $1000 \mathrm{~m}$ distance on the ebb tide within mangroves, when seaward flows are reduced over the high friction vegetated surfaces. Once flows are restricted to the channel system within wetlands, ebb peak velocities may exceed flood peak velocities, thereby acting to maintain the channel system. This phenomenon has also been observed in saltmarshes [Bayliss-Smith et al., 1979].

In a general sense, estuarine studies have shown that the presence of high-friction intertidal surfaces leads to a modification of the progression of the tidal wave into and out of the estuary, such that, where friction is high, the landward increase in tidal high water is counteracted by tidal energy dissipation over those surfaces [Dyer, 1997]. By implication, the loss of such high friction surfaces can thus lead to an increase in tidal high water within the estuary, resulting in a heightened flood risk. Feedback relationships between tidal asymmettry and the transportation and deposition of sediment, however, clearly also operate in the reverse, where high friction surfaces lead to the capture of fine sediments around the flood and ebb slack water phases [Dronkers, 1986].

With respect to protection (water level regulation) during storm surges, the flow retardation over vegetated intertidal surfaces and channelization in the creeks within such surfaces has been incorporated into numerical storm surge models [Wamsley et al., 2010; Loder et al., 2009]. While such models suggest that wetlands have the potential to reduce elevated water levels during surges $(\mathrm{ca}$. $1 \mathrm{~m}$ reduction over $50-60 \mathrm{~km}$ in the case of Louisiana wetlands), this effect has also been shown to be highly sensitive to bathymetry and wetland geomorphology, as well as individual storm characteristics [Wamsley et al., 2010]. Moreover, such models have also highlighted that, in certain circumstances, increases in surge elevations can result from increases in wetland elevations [Loder et al. 2009]. With respect to wetland morphology, Loder et al. [2009] identified the degree of marsh segmentation / fragmentation as being of particular importance to the landward conveyance of the surge. Table 1, adapted from Anderson et al. [2011] lists some of the findings of key field studies to date. 
Table 1. Key field studies on wave dissipation over saltmarsh and mangrove vegetation [adapted from Anderson et al. 2011].

\begin{tabular}{|c|c|c|c|}
\hline Author and year of study & $\begin{array}{l}\text { Distance } \\
(\mathrm{m})\end{array}$ & Dominant species & $\begin{array}{l}\text { Wave height (or energy) reduction } \\
\text { over distance }\end{array}$ \\
\hline Wayne 1976 & 20 & Spartina alterniflora & $\begin{array}{l}77 \% \text { over first } 10 \mathrm{~m}, 66 \% \text { over second } \\
10 \mathrm{~m}\end{array}$ \\
\hline Knutson et al., 1982 & 10 & Spartina alterniflora & $65 \%(88 \%)$ \\
\hline Brinkman et al., 1997 & 150 & Rhizophora spp. & $(50 \%)$ \\
\hline Möller et al., 1999 & 180 & $\begin{array}{l}\text { Mixed saltmarsh community (Limonium vulgare, } \\
\text { Aster Tripolium, Atriplex portulacoides, Salicronia } \\
\text { spp., Spartina spp., Suaeda maritima, Plantago } \\
\text { maritima, Puccinellia maritima }\end{array}$ & $61 \%$ \\
\hline \multirow[t]{2}{*}{ Möller and Spencer, 2002} & 163 & Aster, Suaeda, Puccinellia, Salicornia, Limonium spp. & $(88 \%)$ \\
\hline & 10 & Aster, Suaeda, Puccinellia, Salicornia, Limonium spp. & $(43.8 \%)$ \\
\hline \multirow[t]{3}{*}{ Möller, 2006} & 10 & Spartina anglica, Salicornia spp. & $15-20 \%$ \\
\hline & 10 & Spartina anglica, Salicornia spp. & $11-17 \%$ \\
\hline & 10 & Salicornia spp. & $10-12 \%$ \\
\hline Mazda et al., 2006 & 100 & Sonneratia spp. & $(50 \%)$ \\
\hline Quartel et al., 2007 & 100 & Kandelia candel, Sonneratia sp., Avicennia marina & $74 \%$ \\
\hline Vo-Luong and Massel,2006 & 40 & & $50 \%(50 \%-70 \%$ over $20 \mathrm{~m})$ \\
\hline Lövstedt and Larson, 2010 & $5-14$ & Phragmites australis & $4-5 \%$ per meter \\
\hline Möller et al., 2011 & 4 & Phragmites australis & $(17-72 \%)$ \\
\hline
\end{tabular}

\section{Wind wave dissipation}

As mentioned above, on the time-scale of an individual inundation event, the bio-physical linkage between the vegetation of the coastal wetland and waves that travel across it, is one in which the vegetation elements act, to varying degrees, as passive obstructions to water currents. Progress in understanding the effect that such an obstruction has on the propagation of waves has been achieved through field, physical and numerical modeling.

\section{Early field and modeling studies}

The first published field study of wave height reduction over saltmarshes concerned wind waves of relatively small magnitude $(<5 \mathrm{~cm})$ over short $(10 \mathrm{~m})$ distances within a micro-tidal Spartina alterniflora marsh on the East coast of the United States [Wayne, 1976]. Average energy loss of $77 \%$ and $66 \%$ was recorded in that experiment over the two $10 \mathrm{~m}$ long successive sections of the $20 \mathrm{~m}$ long transect. No additional studies were published until Knutson's [1982] field experiment in which the dissipation of boat generated waves was observed over relatively short $S$. alterniflora marsh transects in Florida. The study by Knutson [1982] reported wave height reductions of, on average, $65 \%$ ( $88 \%$ wave energy loss) over $10 \mathrm{~m}$ marsh surface for waves up to $17 \mathrm{~cm}$ in height. In the UK, basic physical model experiments with assumed additional friction effects over plywood models of seawalls fronted by 'marsh' (berms) suggested that an $80 \mathrm{~m}$ wide macrotidal saltmarsh platform (with a $2 \mathrm{~m}$ high steep seaward 'cliff' and inundation depths of $2 \mathrm{~m}$ above the platform) would reduce incident deep water wave heights of $1.75 \mathrm{~m}$ to less than $0.8 \mathrm{~m}$ at the landward end of the platform [Brampton, 1992]. These early results, based on very specific assumptions about marsh configuration and hydrodynamic conditions, were promptly used by the UK Environment Agency to estimate cost savings on sea walls with fronting saltmarsh, but Table 1 illustrates that estimates based on one individual study must be treated with extreme caution, due to a high spatial and temporal variability within the wave dissipation process.

None of the above early studies considered the effect of varying water depths, varying incident wave conditions, or vegetation type, or indeed, with the exception of the physical scale model of Brampton [1992], included any comparison with unvegetated surfaces in a similar setting. Brampton's model, however, remained untested against field data in macro-tidal marsh settings until the studies of Moeller et al. [1996] and Möller et al. [2002] produced field measurements over macro-tidal marshes on the North Norfolk and Essex coast of the UK. This field data showed good agreement with the model of Brampton: a marsh edge cliff producing a rapid, localized, shoaling of waves, followed by rapid attenuation over the vegetated marsh surface (Fig. 4).

\section{Geomorphological and hydrodynamic contexts}

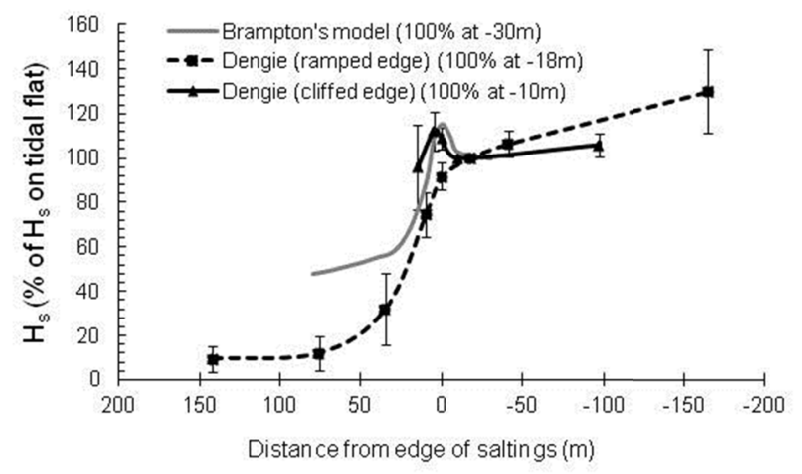

Figure 4. Comparison of wave height reduction along shorenormal transect from right to left: unvegetated tidal flat (negative distances) across the wetland margin (zero distance) and onto the vegetated marsh (positive distances); for model of Brampton [1992] and field data of Möller and Spencer [2002] (see text). 
Both Brampton's model and the Essex coast (Dengie, UK) [Möller et al., 2002] field data set show that, when encountering a cliffed marsh edge, wave height temporarily increases over the submerged cliff, before undergoing a rapid decline, while ramped marsh edges exhibit a smoother, but rapid, reduction in wave energy landward of the marsh edge (Fig. 4), highlighting that wave dissipation over wetland surfaces is a process that is significantly affected by what might be called 'meso-scale morphological variations'. Such variations include the occurrence of morphological features such as cliffs, mud-mounds, tidal creeks, and salt-pans, all of which cause wave refraction, shoaling, diffraction, and breaking, and thus wave energy reduction or transmission over distances of 1-100m [Möller et al., 2002]. Consideration of the effect of such features, however, continues to pose a challenge and is thus rare or absent in studies on wave attenuation over wetland surfaces.

Brampton's model and the field data from Dengie also suggested a rapid, non-linear reduction in wave energy landward of the marsh edge. As might be expected, given the rapid attenuation of the oscillatory wave motion with depth beneath the water surface, however, the data from Dengie shows that the nature of that decline appears to depend on water depth and incident wave energy conditions [Möller et al., 2002] (Fig. 5). A range of studies have followed a similar approach of recording wave dissipation along shore-normal transects in other field settings, e.g. in mangroves [Furikawa et al., 1997; Quartel et al., 2007] and micro-tidal reed bed settings [Lövsted and Larson, 2010; Möller et al., 2011; Möller et al., 2009] under a range of water depth and wave conditions. The review by Gedan et al. [2011], however, highlights that the relationship between wave dissipation, water depth, and incident wave energy remains anything but clear, with contradictory field evidence from different settings and types of vegetation. Aside from the more obvious distinction between fully submerged vegetation canopies (e.g. macro-tidal saltmarshes) and partially emergent vegetation (e.g. micro-tidal settings or mangroves), the varying structural characteristics of different species of vegetation (vertical structure, flexibility/stiffness, buoyancy, and canopy density) most likely

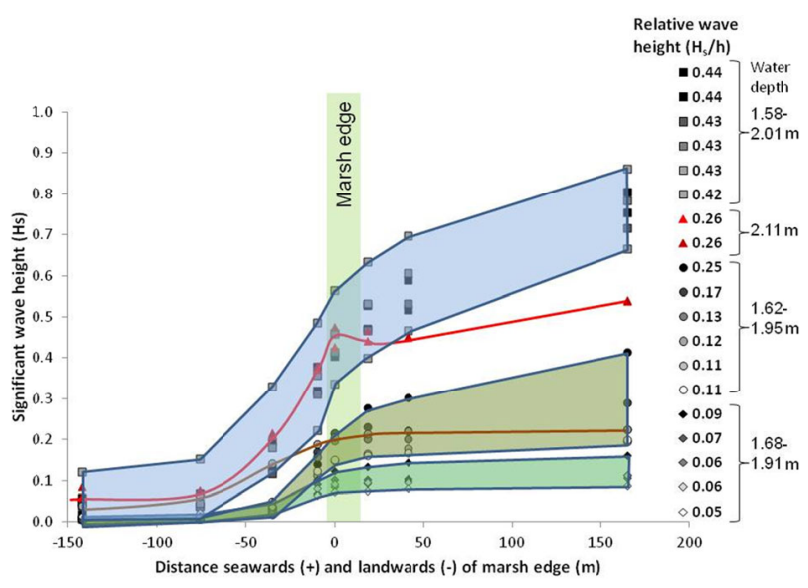

Figure 5. Wave height / water depth control on patterns of shorenormal wave dissipation across unvegetated tidal flat (right side) to vegetated marsh (left side of marsh edge); data from the ramped marsh at Tillingham, Dengie, UK. explain this large variability in field measurement [Möller et al., 2011; Mazda et al., 2006].

\section{The importance of vegetation ch aracteristics}

Field studies that explore the direct linkage between vegetation properties and wave dissipation are still few and far between, but separate studies clearly suggest variations in wave attenuation between species, with, in the case of mangroves, Brinkman et al. [1997], e.g., reporting a $50 \%$ reduction in wave energy over $150 \mathrm{~m}$ of Rhizophora covered surfaces, while Mazda et al. [2006] suggest the same reduction over $100 \mathrm{~m}$ of Sonneratia mangrove in similar conditions. In the case of mangrowes, Mazda et al. [1997 and 2005] have also been able to capture the structural complexity of mangrove trees to a degree and relate the 'effective length scale' $\left(L_{E}\right)$ (the ratio of the proportion of vegetation within a volume of water to the surface area of that vegetation projected into the flow direction) to tidal flow, but not wave, reduction in Rhizophora and Bruguiera mangroves.

In saltmarshes, Möller et al. [1999] reported seasonal variations in wave dissipation over the Dengie marshes, UK, for measurements made under similar hydrodynamic conditions. Such variations may be explained by seasonal changes in vegetation density, although no direct measurements of the latter were included in the study. Möller [2006] found indications of relationships between wave dissipation over short $(20 \mathrm{~m})$ transects of Salicornia, Spartina, and a mixedl canopy, and estimates of the projected area of vegetation obstructing wave-induced flow as derived from photographs of a strip of vegetation of known width taken horizontally against a background plate. In a more detailed field experiment, Neumeier and Amos [2006] found that 10-20\% attenuation of wave orbital-velocities occurred in the denser part of a Spartina canopy below a height of about $30-40 \mathrm{~cm}$ from the bed, where the lateral obstruction by the vegetation, as determined from horizontal photography and biomass estimates, became significant. The importance of vegetation stiffness to wave dissipation was aptly demonstrated by the flume experiments of Bouma et al. [2005] in which relatively stiff Spartina vegetation caused waves to be dissipated approximately three times as efficiently as the more flexible Zostera counterparts. Quantitative relationships between structural properties of wetland vegetation and wave dissipation under particular hydrodynamic conditions, however, are still lacking, though Feagin et al.'s [2010] report on structural measurements of a series of different coastal wetland plant species, provides a step in the right direction.

Vegetation does not necessarily reduce wave or tidal currents at the scale of individual vegetation elements. Furukawa et al. [1997], for example showed that individual mangrove stem and root elements are able to generate significant flow jets and eddies around them, with root-mean-square velocities within those jets equal to three times the mean flow velocity. Furthermore, anecdotal evidence reported from field observations suggests that, where present at low densities on eroding saltmarsh margins, individual saltmarsh plants can interact with incident waves in ways that enhance erosion at the small (plant) scale (Fig. 6(a)). Depending on the spacing between plants, such small scale erosion can then act to initiate large-scale erosion features, such as surface gullies that lead to creek bank mass failure (Fig. 6(b)). Feagin et al. [2009] identify similar effects with respect to roots on exposed marsh cliff sections. 


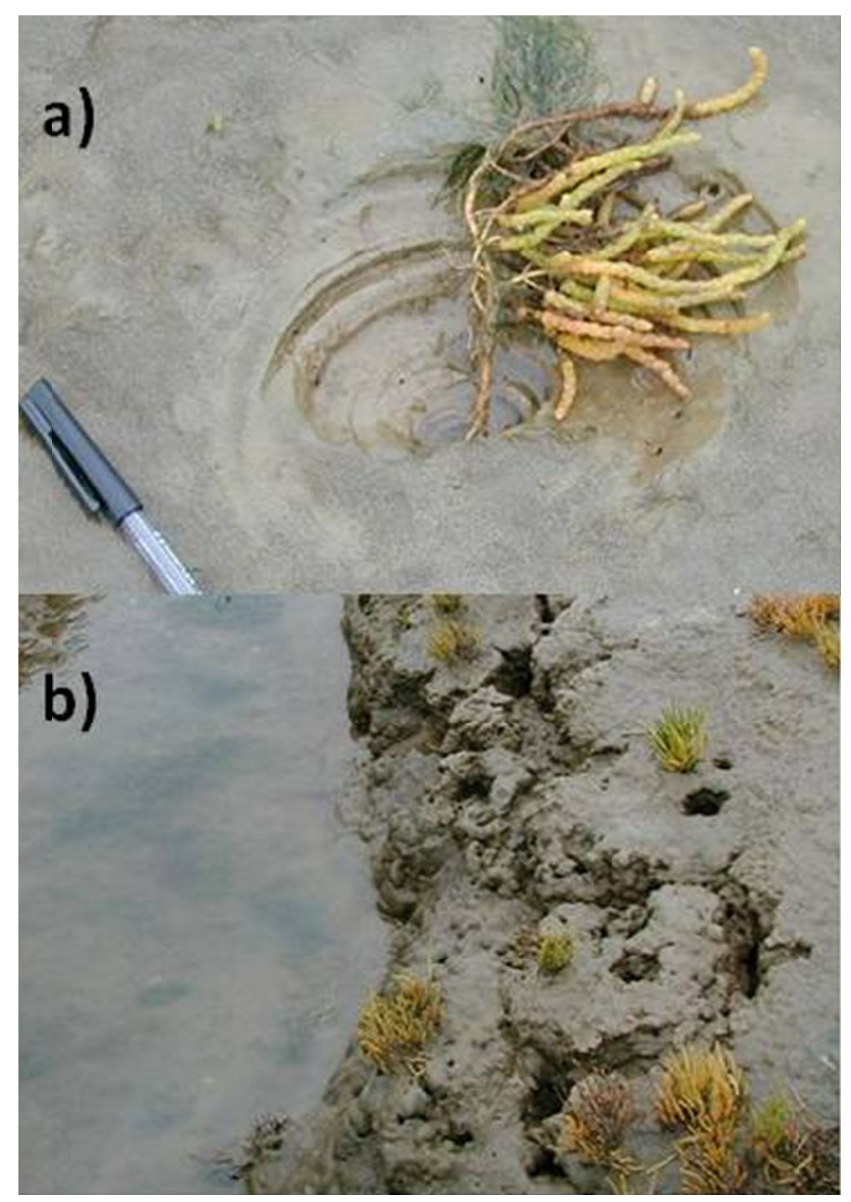

Figure 6. (a) Individual Salicornia plants acting together with wave action as erosive agents, encouraging (b) larger scale erosion features and mass failure of creek bank sediments at Tillingham, Essex, UK (Photograph: I. Möller).

\section{Controlled laboratory experiments}

The recognition that the interaction between the orbital motion of surface waves and the vegetation present at the bed is complex and that this interaction depends on (a) hydrodynamic conditions and (b) vegetation properties has led to several authors investigating the phenomenon under controlled laboratory conditions, of which that of Bouma et al. [2005] has already been mentioned above. One of the key challenges in this context is the need to scale down the vegetation elements and/or hydrodynamic conditions within standard laboratory wave flumes. Thus, such studies have arguably contributed more towards understanding the nature of flow patterns around plant elements than the dependency of the process on vegetation canopy characteristics at the landscape scale, or on water depth and wave height variation.

Due to the physical size of mangrove plants, laboratory flume experiments with natural vegetation are restricted to saltmarsh, reed, or seagrass vegetation. Key studies include those of Fonseca and Cahalan [1992] on four species of seagrass common in the Gulf of Mexico, Coops et al. [1996a and 1996b] on emergent reed (Phragmites), and Tschirky et al.'s [2000] studies using Scirpus americanus vegetation typical of Great Lake wetlands. The seagrass study results indicate that the energy of waves (wave height $<0.05 \mathrm{~m}$ ) can be reduced by as much as $76 \%$ over a $1 \mathrm{~m}$ test section [Fonseca and Cahalan, 1992]. Plant density and water depth were identified as factors that control wave attenuation. Shoot density, however, appeared to be less influential than other factors such as plant morphology, flexibility and movement in affecting flow and wave reduction. Streamlining is important in reducing the area of the plant exposed to the flow and therefore the stress experienced by the plant.

Vegetation in Coops et al.'s [1996ia] experiment was only partly submerged, but exposed to higher waves $(0.23 \mathrm{~m})$. The results indicate much smaller reductions in wave height $(<29 \%)$ than in the seagrass experiment although reductions were significantly higher on the vegetated areas than the unvegetated areas when the vegetation was fully developed. Coops et al. [1996a] also showed that the presence of vegetation can significantly reduce the amount of wave-induced erosion, although the amount of reduction in erosion depends on the type of species, substrate, and surface morphology.

In addition to the positive influence of high stem densities and the negative influence of high water depths on wave attenuation, Tschirky et al.'s [2000] study suggested, contrary to the field studies referred to above, that attenuation increased slightly under larger incident wave heights.

Other studies, such as those of Augustin et al. [2009] have used artificial vegetation, in this case cylindrical wooden dowels and polythene foam tubing. Although valuable for the validation of numerical models that assume a rather simplistic vegetation structure (see below), the limitations of such work become clear when considering the importance of plant flexibility and structure identified by field and flume studies with natural vegetation.

\section{Numerical modeling}

In the absence of field and laboratory observations during extreme water depth / wave energy events, when the capacity of wetlands to act as a sea defense becomes of greatest interest to coastal managers and engineers, numerical modeling offers one avenue to at least assess whether the fundamental physics of the process of wave attenuation by vegetation has been adequately understood theoretically and can be mathematically captured.

The numerical modeling of wave attenuation over wetland surfaces has to account for wave breaking in the reduced water depth and for drag and inertial forces around the vegetation elements. Wave energy dissipation due to wave breaking is largely a function of wave parameters (wave height, length, and period) and water depth (i.e., the morphology of the intertidal zone) and can be numerically approximated if these parameters are known. The drag and inertial forces induced by the 'rough' vegetation cover, however, are more difficult to parameterize. The correct representation of the biomechanics of the vegetation elements is clearly critical in this regard. While the representation of vegetation as simple vertical cylinders has been commonly adopted [e.g. Dalrymple et al., 1984; Dean and Bender, 2006] this is not always appropriate, in particular, where plant structure is complex (such as in the common North-west European saltmarsh species Atriplex portulacoides) or species are flexible (such as in the case of seagrass or kelp).

One of the earlier studies to recognize the importance of representing the swaying motion of submerged or partially submerged vegetation in wave transformation models is that by Knutson et al. [1982]. He incorporated an empirical drag coefficient, $C_{P}$, into his model, such that the rate of wave height 
reduction from incident waves $\left(H_{0}\right)$ to waves a certain distance $(x)$ across the wetland can be expressed as a function of the bulk drag coefficient of the entire canopy $\left(C_{D}\right)$, average plant stem diameter $(d)$, average stem spacing $(\Delta s)$, water depth $(h)$, and incident wave height $\left(H_{0}\right)$ :

$$
\frac{H}{H_{0}}=\frac{1}{1+A x}
$$

\section{Where:}

$$
A=\frac{C_{P} C_{D} d}{6 \pi \Delta s^{2} h} H_{0}
$$

Based on field measurements gathered by observing the reduction of boat generated waves over Spartina alterniflora marshes in Chesapeake bay, a value of 5 was determined for $C_{P}$ as leading to the best prediction of observed attenuation. Most numerical approaches towards representing the interaction between plants and waves involve the incorporation of a plantdependent drag coefficient of a similar nature (and its inverse relationship to the Reynolds number [see e.g. Asano et al., 1992]) and this approach has since been expanded by, for example, Mendez and Losada [2004] with validation and calibration against results from laboratory experiments with artificial kelp.

More recently, however, alternative algebraic model formulations suggest that, for highly flexible vegetation at least, the resistance resulting from the presence of a group of plant elements can be as much as four times that derived from a simple summation of the drag imposed by individual stems [Anderson et al., 2011].

\section{Tsunami protection}

Although mangroves have been thought to act as coastal protection in a more general sense, the Asian tsunami of 2004 caused much debate about their actual effectiveness as tsunami protection and the means by which this is achieved. Anecdotal evidence abounds as to the protection that was afforded by fringing mangrove areas to landward lying communities [Danielsen et al., 2005; Baird and Kerr, 2008], but the sudden and unpredictable nature of tsunami events as well as the large canopy size of mangrove forests makes this effect less easy to study by field and physical model approaches.

The long length and period and high velocity $(430 \mathrm{~km}, 37 \mathrm{~s}$, and $200 \mathrm{~ms}^{-1}$ in the case of the 2004 tsunami [Spencer, 2007]) mean that the impact of a tsunami wave on coastal vegetation differs significantly from that of storm generated waves or raised water levels under a meteorological surge. Such waves generate extreme wave run-up in very short periods of time upon arrival at the coast (up to $50 \mathrm{~m}$ run-up above mean sea level (MSL) near the earthquake epicenter in Sumatra in 2004 [Spencer, 2007]).

Under such extreme hydrodynamic impact, mangrove vegetation itself can suffer significant damage (as it did in 2004 [see Dam Roy and Krishnan, 2005]) and, while, in the process of suffering this damage, water levels and flows may well be reduced, the destruction of the vegetation leaves the coast more vulnerable to high wave action than before the event. In addition, the debris created by mangrove destruction, interacts with the flow of water during the event, potentially blocking or diverting water flows. Teo et al. [2009], in their attempt to model the effect of mangrove vegetation on a tsunami, describe a two-fold approach of (i) increased drag (friction) as introduced by mangrove presence, and (ii) the effect of the mangrove in blocking the flow of water due to the specific 'porosity' of the mangrove forest. The likelihood of mangrove damage during the passage of a tsunami, however, creates a difficulty in modeling the sea defense function, as both friction and blockage effects are likely to change during an individual event.

Bearing these difficulties in mind, however, existing studies suggest that key controls on the efficiency with which mangroves attenuate tsunamis are bathymetry and coastal configuration and mangrove species (and species composition) [see Spencer and Möller, 2012]. Thus, Hiraishi and Harada [2003], for example, modeled a decrease in the maximum flow pressure (in $\mathrm{N} \mathrm{m}^{-2}$ ) with increasing mangrove tree density, using data from the 1998 tsunami in Papua New Guinnea.

\section{FUTURE CHALLENGES}

Much progress has been made in recent years on better understanding bio-physical linkages within coastal wetland systems. The disciplinary boundary between ecological studies into coastal wetland functioning and geological and geomorphological studies into landform evolution has become less divisive in the context of the growing recognition of ecosystem service provisioning by wetlands. An increasing number of studies now appreciate the tight linkage between the presence of vegetation and benthic fauna and the water and sediment fluxes through and across the wetland system. Arguably, two key challenges remain, however, regarding our understanding of how bio-physical linkages affect the sea defense function of coastal wetlands.

Firstly, there is the issue of scale-dependency of the varying marsh characteristics that determine coastal protection functions. At small spatial scales of $1-10 \mathrm{~m}$, the effect of wetland surfaces on wave dissipation, for example, can be understood as a function of parameters that can be recorded at discrete and distinct locations along the cross-shore profile (notably vegetation type, structure, and density, as well as water depth and incident wave energy). At larger spatial scales of $10-100 \mathrm{~m}$ wave refraction and diffraction through surface topographical features (creeks and salt pans for example) are likely to become equally important or at least cannot be ignored. At those larger scales, however, it is still unclear how vegetation type, structure, and density might be most suitably parameterized and measured in practice (so as to link them to the wave dissipation effect), at least where vegetation cover is patchy and non-uniform. How best to aggregate those vegetation characteristics relevant to the wave dissipation function of coastal wetlands in patchy communities (such as those typical of mature, mixed European salt marsh communities) at the larger, marshwide, scale remains a fundamental challenge for future research.

Secondly, growing evidence from extreme events such as hurricanes in the Gulf of Mexico (in the case of surge and wave dissipation) and the Asian tsunami, illustrates the importance of the quantification of process thresholds or 'tipping points'. Such thresholds can be conceptualized as describing the switching from a system in which the biological elements act to mediate hydrodynamic energy (such as the reduction in surge elevations, 
flow velocities, or wind generated waves) to one in which the presence of biological elements enhances the erosive impact of water flows (such as in sparsely vegetated marshes with high incident wave energy (Fig. 5) or where mangrove debris adds to the destructive impact of tsunami waves propagating inshore). Any serious incorporation of bio-physical linkages into coastal management plans requires some assessment of the likelihood with which such process thresholds may be exceeded within a given time frame and further research is thus required to identify where those process thresholds lie.

Thus, while much progress has been made in understanding biophysical linkages in saltmarsh systems, for this knowledge to be used successfully in predictive models that evaluate the sea defense function of coastal wetlands for the purpose of its incorporation into coastal management approaches, progress in these two areas is now needed.

\section{ACKNOWLEDGEMENT}

This review and the thoughts expressed therein result from many years of research and this includes a range of research projects funded, amongst others, by the UK Environment Agency, The Royal Society, the Natural Environment Research Council (NERC), and the UK Department for the Environment and Rural Affairs (DEFRA). I am indebted to Dr T Spencer for collaboration on most of those projects and for fruitful discussions over the years. I am also grateful to Dr A McIvor for very useful shortnotice comments on the text.

\section{REFERENCES}

Allen, J.R.L. (2000), Morphodynamics of Holocene saltmarshes, a review sketch from the Atlantic and Southern North Sea coasts of Europe, Quaternary Science Reviews 2000, 19,1155-1231.

Allen, J.R.L. and K. Pye (eds) (1992), Saltmarshes, Morphodynamics, conservation and engineering significance. Cambridge University Press, Cambridge.

Anderson, M.E., J. McKee Smith, and S.K. McKay (2011), Wave dissipation by vegetation. US Army Corps of Engineers. Note ERDC/CHL CHETN-I-82, 22pp.

Asano, T., H. Deguchi, and N. Kobayashi (1992), Interactions between water waves and vegetation. Proceedings of the 23rd International Conference on Coastal Engineering, ASCE, 27102723.

Augustin, L.N., J.L. Irish, and P. Lynett (2009), Laboratory and numerical studies of wave damping by emergent and nearemergent wetland vegetation, Coastal Engineering, 56(3), 332340.

Baird, A.H., and A.M. Kerr (2008), Landscape analysis and tsunami damage in Aceh, comment on Iverson \& Prasad (2007), Landscape Ecology, 23, 3-5.

Bayliss-Smith, T.P., R. Healey, R. Lailey, T. Spencer, and D.R. Stoddart (1979), Tidal flows in salt marsh creeks, Estuarine and Coastal Marine Science, 9, 235-255.

Beaumont, N.J., M.C. Austen, S.C. Mangi, and M. Townsend (2008), Economic valuation for the conservation of marine biodiversity, Mar. Poll. Bull., 56, 386-396.

Bouma, T.J., M.B. De Vries, G. Peralta, I.C. Tanczos, J. van de Koppel, and P.M.J. Herman (2005), Trade-offs related to ecosystem engineering, a case study on stiffness of emerging macrophytes, Ecology, 86, 2187-2199.

Bouma T.J., M. Friedrichs, B.K. van Wesenbeek, S. Temmerman, G. Graf, and P.M.J. Herman (2009), Density dependent linkage of scale-dependent feedbacks, a flume study on the intertidal macrophyte Spartina anglica, Oikos, 118, 260-268.

Brampton, A.H. (1992), Engineering significance of British saltmarshes. In: Allen, J.R.L., and K. Pye (eds) Saltmarshes. Morphodynamics, conservation and engineering significance. Cambridge University Press, Cambridge.

Brinkman, R.M., S.R. Massel, P.V. Ridd, and K. Furakawa (1997), Surface wave attenuation in mangrove forests. Proceedings, 13th Australasian Coastal and Ocean Engineering Conference, 2, 941-979.

Cahoon, D.R., P.F. Hensel, T. Spencer, D.J. Reed, K.L. McKee, and N. Saintilan (2006), Coastal wetland vulnerability to relative sea level rise, Wetland elevation trends and process controls. In Verhoeven, T.A., B. Beltan, R. Bobbink, and D.F. Whigham (eds), Wetlands and Natural Resource Management. Ecological Studies, 190, 271-292. Springer, Berlin.

Cahoon, D.R. (2006), A review of major storm impacts on coastal wetland elevations, Estuaries and Coasts, 29(6A), 889-898.

Chmura, G.L., S. Anisfeld, D. Cahoon, and J. Lynch (2003) Global carbon sequestration in tidal, saline wetland soils, Global Biogeochemical Cycles, 17, 1-12.

Christiansen, T., P.L. Wiberg, and T.G. Milligan (2000) Flow and sediment transport on a tidal salt marsh surface, Estuarine, Coastal, and Shelf Science, 50, 315-331.

Coops, H., N. Geilen, H.J. Verheij, R. Boeters, and G. van der Velde (1996a) Interactions between wave, bank erosion and emergent vegetation, an experimental study in a wave tank, Aquatic Botany, 53, 187-198.

Coops, H., and G. van der Velde (1996b) Effects of waves on helophyte stands, mechanical characteristics of stems of Phragmites australis and Scirpus lacustris, Aquatic Botany, 53, 175-185.

Cowell, P.J., and B.G. Thom (1994) Morphodynamics of coastal evolution. In: Carter, R.W.G., and C.D. Woodroffe (eds) Coastal evolution, late Quaternary shoreline morphodynamics, Cambridge University Press, Cambridge, 33-86.

Dabalà, C., N. Calace, P. Campostrini, M. Cervelli, F. Collavini, L. Da Ros, A. Libertini, A. Marcomini, C. Nasci, D. Pampanin, B.M. Petronio, M. Pietroletti, G. Pojana, R. Trisolini, L. Zaggia, and R. Zonta (2005), Water quality in the channels of venice, Results of a recent survey. In: Fletcher, C.A., and T. Spencer (2005), Flooding and Environmental Challenges for Venice and its Lagoon, Cambridge, Cambridge University Press, 617-630.

Dalrymple, R., J. Kirby, and P. Hwang (1984) Wave diffraction due to areas of energy dissipation, Journal of Waterway, Port, Coastal and Ocean Engineering, 10(1), 67-79.

Dam Roy, S., and P. Krishnan (2005), Mangrove stands of Andamans vis-a '-vis tsunami, Current Science, 89, 1800-1804.

Danielsen, F., M.K. Sørensen, M.F. Olwig, V. Selvam, F. Parish, N.D. Burgess, T. Hiraishi, V.M. Karunagaran, M.S. Rasmussen, L.B. Hansen, A. Quarto, and N. Suryadiputra (2005), The Asian tsunami, a protective role for coastal vegetation, Science, 310, 643.

Dean, R.G., and C.J. Bender (2006), Static wave setup with emphasis on damping effects by vegetation and bottom friction, Coastal Engineering, 53, 149-156. 
Dronkers, J. (1986), Tidal Asymmetry and Estuarine Morphology, Neth. J. Sea Res., 20(2/3), 117-131.

Dyer, K.R. (1997), Estuaries, A Physical Introduction. John Wiley and Sons, London.

Feagin, R.A., J.L. Irish, I. Möller, W.M. Williams, R.J. ColonRivera, and M.E. Mousavi (2010), Short communication, Engineering properties of wetland plants with application to wave attenuation, Coastal Enginering, 58(3), 252-255.

Feagin, R.A., S.M. Lozada-Bernard, T.M. Ravens, I. Möller, K.M. Yeager, and H.H. Baird (2009), Does vegetation prevent wave erosion of salt marsh edges?, Proceedings of the National Academy of Sciences of the United States of America, 106(25), 10109-10113.

Fonseca, M.S., and J.A. Cahalan (1992), A preliminary evaluation of wave attenuation by four species of seagrass, Estuarine, Coastal and Shelf Science, 35, 565-576.

Fonseca, M.S., J.S. Fisher, J.C. Zieman, and G.W. Thayer (1982), Influence of the seagrass, Zostera maina L., on current flow, Estuarine, Coastal and Shelf Science, 15, 351-364.

French, J.R. (2006). Tidal marsh sedimentation and resilience to environmental change, exploratory modelling of tidal, sea-level and sediment supply forcing in predominantly allochthonous systems, Marine Geology, 235, 119-136.

Furukawa, K., E. Wolanski, and H. Mueller (1997), Currents and sediment transport in mangrove forests, Estuarine, Coastal and Shelf Science, 44, 301-310.

Gedan, K.B., M.L. Kirwan, E. Wolanski, E.B. Barbier, and B. Silliman (2010), The present and future role of coastal wetland vegetation in protecting shorelines, answering recent challenges to the paradigm, Climate Change, 106, 7-29. doi, 10.1007/s10584-010-0003-7.

Hiraishi, T., and K. Harada (2003), Greenbelt tsunami prevention in South Pacific region, Available from, /eqtap.edm.bosai.go.jp/ useful_outputs/report/hiraishi/data/papers/greenbelt.pdfrS.

Knutson, P.L., R.A. Brochu, W.N. Seelig, and M. Inskeep (1982), Wave damping in Spartina alterniflora marshes, Wetlands, 2, 87-104.

Koch, E.W., E.B. Barbier, B.R. Silliman, D.J. Reed, G.M.E. Perillo, S.D. Hacker, E.F. Granek, J.H. Primavera, N. Muthiga, S. Polasky, B.S. Halpern, C.J. Kennedy, C.V. Kappel, and E. Wolanski (2009), Non-linearity in ecosystem services, temporal and spatial variability in coastal Protection, Front Ecol Environ 2009, 7(1), 29-37, doi,10.1890/080126

Krauss, K.W., T.W. Doyle, T.J. Doyle, C.M. Swarzenski, A.S. From, R.H. Day, and W.H. Conner (2009), Water level observations in mangrove swamps during two hurricanes in Florida, Wetlands, 29(1),142-149.

Leonard, L.A., and M.E. Luther (1995), Flow hydrodynamics in tidal marsh canopies, Limnology and Oceanography, 40 (8), 1474-1484.

Loder, N.M., J.L. Irish, M.A. Cialone, and T.V. Wamsley TV (2009), Sensitivity of hurricane surge to morphological parameters of coastal wetlands, Estuarine, Coastal, and Shelf Science, 84(4), 625-636.

Lövstedt, C.B., and M. Larson (2010), Wave damping in Reed, Field measurements and mathematical modelling, Journal of Hydraulic Engineering, 136(4), 222-233.

Mazda, Y., D. Kobashi, and S. Okada (2005), Tidal scale hydrodynamics within mangrove swamps, Wetlands Ecology and Management, 13, 647-655.
Mazda, Y., M. Magi, Y. Ikeda, T. Kurokawa, and T. Asano (2006), Wave reduction in a mangrove forest dominated by Sonneria sp, Wetlands Ecology and Management, 14, 365-378.

Mazda, Y., E. Wolanski, B. King, A. Sase, D. Ohtsuka, and M. Magi (1997), Drag force due to vegetation in mangrove swamps. Mangroves and Salt Marshes, 1, 193-199.

MEA (Millennium Ecosystem Assessment) (2005), Ecosystems and Human Wellbeing, Synthesis, Island Press, Washington, DC.

Méndez, F.J., and I.J. Losada (2004), An empirical model to estimate the propagation of random breaking and nonbreaking waves over vegetation fields, Coastal Engineering, 51(2), 103118.

Moeller, I., T. Spencer, and J.R. French (1996), Wind wave attenuation over saltmarsh surfaces, Preliminary results from Norfolk, England, Journal of Coastal Research, 12(4), 10091016.

Möller, I. (2006), Quantifying saltmarsh vegetation and its effect on wave height dissipation, results from a UK East coast saltmarsh, Journal of Estuarine, Coastal, and Shelf Sciences, 69(3-4), 337-351.

Möller, I., T. Spencer, J.R. French, D.J. Leggett, and M. Dixon (1999), Wave transformation over salt marshes, A field and numerical modelling study from North Norfolk, England, Estuarine, Coastal and Shelf Science, 49, 411-426.

Möller, I., T. Spencer, and J. Rawson (2002), Spatial and temporal variability of wave attenuation over a UK East-coast saltmarsh, Proceedings of the $38^{\text {th }}$ International Conference on Coastal Engineering, Cardiff, July 2002.

Möller, I., J. Lendzion, T. Spencer, A. Hayes, and S. Zerbe (2009), The sea-defense function of micro-tidal temperate coastal wetlands, In: Brebbia, C.A., G. Benassai, and G.R. Rodriguez (eds), Coastal Processes, WIT Transactions on Ecology and the Environment, 126, 51-62.

Möller, I., J. Mantilla-Contreras, T. Spencer, and A. Hayes (2011), Micro-tidal coastal reed beds, Hydro-morphological insights and observations on wave transformation from the southern Baltic Sea, Estuarine, Coastal and Shelf Science, 92(3), 424436.

Morris, J.T., P.V. Sundareshwar, C.T. Nietch, B. Kjerfve, and D.R. Cahoon (2002), Responses of Coastal Wetlands to Rising Sea Level, Ecology, 83, 2869-2877.

Neumeier, U,. and C.L. Amos (2006), The influence of vegetation on turbulence and flow velocities in European salt-marshes. Sedimentology, 53(2), 259-277.

Quartel, S., A. Kroon, P.G.E.F. Augustinus, P. Van Santen, and N.H. Tri (2007), Wave attenuation in coastal mangroves in the Red River Delta, Vietnam, Journal of Asian Earth Sciences, 29, 576-584.

Shepard, C.C., C.M. Crain, and M.W. Beck (2011), The protective role of coastal marshes, A systematic review and meta-analysis, PLoS ONE, 6(11), e27374. doi,10.1371/journal.pone.0027374

Shi, Z., J.S. Pethick, and K. Pye (1995), Flow structure in and above the various heights of a saltmarsh canopy, a laboratory flume study, Journal of Coastal Research, 11(4), 1204-1209.

Spencer, T., and I. Möller (2012), Mangrove Systems, In: Sherman, D.J. (ed.), Coastal Geomorphology (Treatise in Geomorphology Vol. 10), Elsevier, Amsterdam. 
Spencer, T. (2007), Coral reefs and the tsunami of 26 December 2004 , generating processes and ocean-wide patterns of impact, Atoll Research Bulletin, 544, 1-36.

Tanaka, N., Y. Sasaki, M.I.M. Mowjood, K.B.S.N. Jinadasa, and S. Homchuen (2007), Coastal vegetation structures and their functions in tsunami protection, experience of the recent Indian Ocean tsunami, Landscape Ecological Engineering, 3, 33-45.

Teo, F.Y., R.A. Falconer, and B. Lin (2009), Modelling effects of mangroves on tsunamis, Water Manag., 162, 3-12.

Tschirky, P., K. Hall, and D. Turcke (2000), Wave attenuation by emergent wetland vegetation, Proceedings of the 27th International Conference on Coastal Engineering, ASCE, 865877.

UK NEA (UK National Ecosystem Assessment) (2011), The UK National Ecosystem Assessment Technical Report, UNEPWCMC, Cambridge.

Vermaat, J.E., and U. Thampanya (2006), Mangroves mitigate tsunami damage, a further response, Estuarine, Coastal and Shelf Science, 69, 1-3.
Vo-Luong, H.P., and S.R. Massel (2006), Experiments on wave motion and suspended sediment concentration at Nang Hai, Can Gio mangrove forest, Southern Vietnam, Oceanologia, 48, 23 40.

Wamsley, T.V., M.A. Cialone, J.M. Smith, J.H. Atkinson, and J.D. Rosati (2010), The potential of wetlands in reducing storm surge, Ocean Engineering, 37, 59-68.

Wamsley, T.V., M.A. Cialone, J.M. Smith, B.A. Ebersole, and A.S. Grzegorzewski (2009), Influence of landscape restoration and degradation on storm surge and waves in southern Louisiana, Natural Hazards; 51: 207-224.

Wayne, C.J. (1976), The effects of sea and marsh grass on wave energy, Coastal Research Notes; 4 (7): 6-8.

Wolanski, E., Y. Mazda, and P. Ridd (1992), Mangrove hydrodynamics, In: Robertson, A.I., and D.M. Alongi DM (eds), Tropical Mangrove Ecosystems, American Geophysical Union, Washington, DC, 4-62.

Woodroffe, C.D. (2002), Coasts: Form, process and evolution, Cambridge University Press, Cambridge. 